\title{
Household costs among patients hospitalized with malaria: evidence from a national survey in Malawi, 2012
}

Ian Hennessee ${ }^{1 *}$, Jobiba Chinkhumba², Melissa Briggs-Hagen ${ }^{1}$, Andy Bauleni ${ }^{2}$, Monica P. Shah', Alfred Chalira ${ }^{3}$, Dubulao Moyo ${ }^{3}$, Wilfred Dodoli ${ }^{4}$, Misheck Luhanga ${ }^{3}$, John Sande ${ }^{3}$, Doreen Ali ${ }^{3}$, Julie Gutman ${ }^{1}$ (D), Kim A. Lindblade', Joseph Njau' and Don P. Mathanga²

\begin{abstract}
Background: With 71\% of Malawians living on $<\$ 1.90$ a day, high household costs associated with severe malaria are likely a major economic burden for low income families and may constitute an important barrier to care seeking. Nevertheless, few efforts have been made to examine these costs. This paper describes household costs associated with seeking and receiving inpatient care for malaria in health facilities in Malawi.

Methods: A cross-sectional survey was conducted in a representative nationwide sample of 36 health facilities providing inpatient treatment for malaria from June-August, 2012. Patients admitted at least $12 \mathrm{~h}$ before study team visits who had been prescribed an antimalarial after admission were eligible to provide cost information for their malaria episode, including care seeking at previous health facilities. An ingredients-based approach was used to estimate direct costs. Indirect costs were estimated using a human capital approach. Key drivers of total household costs for illness episodes resulting in malaria admission were assessed by fitting a generalized linear model, accounting for clustering at the health facility level.

Results: Out of 100 patients who met the eligibility criteria, 80 (80\%) provided cost information for their entire illness episode to date and were included: $39 \%$ of patients were under 5 years old and $75 \%$ had sought care for the malaria episode at other facilities prior to coming to the current facility. Total household costs averaged $\$ 17.48$ per patient; direct and indirect household costs averaged $\$ 7.59$ and $\$ 9.90$, respectively. Facility management type, household distance from the health facility, patient age, high household wealth, and duration of hospital stay were all significant drivers of overall costs.

Conclusions: Although malaria treatment is supposed to be free in public health facilities, households in Malawi still incur high direct and indirect costs for malaria illness episodes that result in hospital admission. Finding ways to minimize the economic burden of inpatient malaria care is crucial to protect households from potentially catastrophic health expenditures.
\end{abstract}

Keywords: Malaria, Household costs, Malawi, Inpatient malaria, Economic burden

\footnotetext{
${ }^{*}$ Correspondence: ihennessee@cdc.gov

${ }^{1}$ Malaria Branch, Division of Parasitic Diseases and Malaria, Center

for Global Health, Centers for Disease Control and Prevention, Atlanta,

GA, USA

Full list of author information is available at the end of the article
} 


\section{Background}

Despite significant reductions in malaria burden in recent years, malaria remains a major cause of morbidity and mortality in Malawi. With an estimated 3.3 million malaria cases and 7200 deaths in 2015, malaria accounts for $34 \%$ of all outpatient consultations and remains the leading cause of death among children under 5 years old [1,2]. Prompt case management of malaria with an effective first-line medication is a cornerstone of malaria control policy in Malawi. Correct management of uncomplicated Plasmodium falciparum malaria with artemisinin-based combination therapy (ACT), and management of severe malaria with parenteral artesunate or quinine contributes to reducing malaria mortality $[1,3]$. Likewise, early diagnosis and treatment of severe malaria is associated with significantly reduced mortality rates [4]. Although the importance of early detection and treatment of malaria episodes is widely recognized, prompt diagnosis and effective treatment remains limited in Malawi. In the 2014 malaria indicator survey (MIS), a nationally representative household survey, only $59 \%$ of children with recent history of fever sought care and $42 \%$ received an antimalarial [5].

The perceived and actual financial costs of care for malaria are important barriers to accessing prompt and effective malaria treatment and these costs can be economically catastrophic for many households [6-8]. In a review of 65 studies conducted in over 15 countries in sub-Saharan Africa including Malawi, mean direct household costs for the treatment of uncomplicated malaria ranged from $\$ 0.30$ ( $\$ 0.34$ in constant 2012 dollars) in Tanzania to $\$ 6.54$ ( $\$ 6.97$ in constant 2012 dollars) in Mozambique $[8,9]$ (pers. comm., Njau and McFarland). While information on the household costs of severe or inpatient malaria is less available, studies have observed costs between $\$ 6.40$ ( $\$ 8.82$ in constant US dollars) in Ghana to $\$ 17.20$ (\$22.30 in constant US dollars) in Sudan $[10,11]$. Given that more than half of the population of Malawi lives below the national poverty level, and $71 \%$ lives on less than $\$ 1.90$ a day [12], the cost of malaria treatment may be prohibitive for many households, potentially resulting in delayed care seeking and inadequate treatment [13]. Despite negotiated prices and subsidies, ACT remains more expensive than previous first-line medications such as sulfadoxine-pyrimethamine or chloroquine [14]. When direct payments for malaria care are removed, patients are significantly more likely to seek care for malaria episodes [15].

Few studies have examined the household costs of uncomplicated malaria and febrile illness treatment in Malawi and there are virtually no studies that have evaluated the household costs of inpatient malaria treatment. One study in 2004 found that mean reported direct costs per febrile episode amount to $\$ 1.05$ (or $\$ 1.28$ in constant US 2012 dollars) in urban areas compared to $\$ 0.21$ (\$0.26 in constant 2012 dollars) in rural areas [16]. These costs are particularly burdensome for very low income households; an earlier study found the total costs of malaria treatment consume almost $30 \%$ of annual income in very low income households, compared to $2 \%$ of income in low to high income households [17]. Many Malawians experience multiple malaria episodes per year [18], which multiplies the economic burden of malaria care on households. Direct costs associated with treatment-seeking vary with distance to health facilities; another study found harder-to-reach households incurred higher costs per fever episode (\$5.24; \$5.52 in constant 2012 dollars) compared to those who lived nearer to health facilities (\$4.46; \$4.70 in constant 2012 dollars) [19]. However, there are little to no data about the household costs of malaria illnesses requiring inpatient management in Malawi.

In order to ensure equitable access to malaria treatment, especially among the most vulnerable populations, it is essential to understand the household costs of inpatient management of malaria. This study examines the direct and indirect household costs associated with malaria illness episodes resulting in inpatient treatment in Malawi, as well as the most important drivers of those costs. This analysis was conducted within a larger study of inpatient malaria case management at public and private nonprofit mission health facilities in Malawi. The study assessed different aspects of facility readiness to manage malaria cases, including availability of antimalarial and other supplies, availability of malaria diagnostic services, health worker training and adherence to national guidelines for the diagnosis and treatment of severe malaria. Details of this study are published elsewhere [20].

\section{Methods \\ Study setting}

Malaria is endemic throughout Malawi, where the entire population of 17.2 million is considered at risk [1]. All three regions of the country experience stable, high levels of transmission, although there is significant seasonal variation, with higher transmission during the rainy season from November to April in most parts of the country [21]. The most recent MIS (2014) found that 33.2\% of children aged 6-59 months were parasitaemic by microscopy [5]. Artemether-lumefantrine (AL) is the recommended first-line treatment for uncomplicated malaria while intravenous quinine or artesunate are recommended for severe malaria episodes. Oral quinine is recommended for pregnant women in their first trimester and children under $5 \mathrm{~kg}$ [22]. 
Health care is delivered free of charge at Ministry of Health $(\mathrm{MoH})$ facilities, whereas Christian Health Association of Malawi (CHAM) facilities receive some government subsidies but charge a nominal fee [19]. An essential health package (EHP), including basic care for malaria and other common infectious diseases, is delivered free of charge at both types of facilities. Primary care is offered by a cadre of village clinics staffed by community health workers (CHWs), health centres, and hospitals, whereas secondary care is typically provided at rural and district hospitals [22].

\section{Sampling and eligibility}

A nation-wide, cross-sectional survey was conducted in 36 health facilities from June through August of 2012. The sampling strategy is described in more detail elsewhere [20]. Briefly, these facilities were systematically selected with equal probability from a list of all $91 \mathrm{MoH}$ and CHAM facilities in Malawi that admit patients for severe malaria. Private, for profit health clinics, which typically do not have inpatient care capacity, were excluded from the sampling frame. The eligible facilities were listed first in order of region, then in order of management (MoH or CHAM), and lastly in order of hospital type (district, community, or other) prior to systematic random selection.

Patients were eligible to participate in the inpatient interview if they had been admitted with any malaria diagnosis, or admitted with another diagnosis but started on an anti-malarial treatment, at least $12 \mathrm{~h}$ prior to the initial arrival of the study team. Patients who were to be discharged on the day of the interview or had sought care at another facility before hospital admission were eligible to provide information on household costs associated with their present malaria episode. Caregivers were asked to respond for patients aged $<12$ years or those unable to speak for themselves.

\section{Data collection and outcome definitions}

Trained interviewers used Dell Axim X51 personal digital assistants (PDAs) to collect demographic and cost information from eligible patients or their caregivers. The questionnaires were programmed in visual CE (Syware, Boston MA). Questionnaires elicited demographic information for patients and their caregivers (e.g., age and sex) and information about the patient's current malaria episode and treatment seeking (e.g., number of days ill, distance from a patient's home to the present facility). Information on household assets and economic characteristics was also elicited. Patients were then asked to provide cost information for their visit to the current facility as well as any previous visits to health facilities for the current malaria episode. Total costs associated with malaria episodes resulting in inpatient admission was considered the primary outcome, while direct and indirect costs were secondary outcomes.

\section{Costing approach}

Direct medical and non-medical costs were estimated using an ingredients-based approach in which the patient or caregiver was asked to recollect the costs incurred for individual items throughout their illness episode [23, 24]. Direct costs were subdivided into two categories: (i) medical costs, and (ii) non-medical costs. Direct medical costs included costs for registration, consultation, supplies, hospital bed, and medications. Direct non-medical costs included travel, meals, and accommodation.

Indirect costs were estimated using a human capital approach $[25,26]$. For patients 14 years and older, productive time lost was estimated as the total number of days spent travelling to and from the facility, waiting for admission, and days spent in care as well as time spent ill prior to seeking care for their current malaria episode. Productive lost time for accompanying caregivers was similarly estimated as the total number of days spent accompanying the patient while travelling to and from the facility, waiting for the patient to be admitted, and accompanying the patient while he or she received care as well as time spent caring for the patient while they were ill prior to seeking care for their current malaria episode. Given the high level of self or informal employment in the country, the national minimum daily wage (317 Malawi Kwacha (MWK), or about USD \$1.30, in 2012 [27]) was used to value the cost of time lost. Associated costs due to lost productivity were estimated as the product of total time lost and the minimum wage. For children below the minimum age for employment in Malawi (<14 years old), only productivity losses for their accompanying caregivers were considered [28]. Additionally, lost school fees due to absenteeism were not included. Total household costs associated with each illness episode resulting in inpatient management were obtained by summing total direct and indirect costs for each health facility visit over the course of the entire illness episode.

\section{Statistical analysis}

All statistical analyses were performed using SAS version 9.4 (SAS institute, Cary, NC) and STATA IC/14 (Statacorp LP, Texas, USA). Frequencies and cross tabulations on patient demographics and mean and median direct and indirect costs were calculated using survey procedures with a cluster statement to account for clustering of individual observations at the health facility level. Household wealth index was calculated from household characteristic and asset data using principal component analysis [29]. Households were then divided into 
household wealth tertiles (poorest, middle and least poor) according to their wealth index score. Given the highly-skewed nature of the cost data (see below for more details on model choice and justification), generalized linear models (GLM) using maximum likelihood estimation were fit to examine bivariate associations between individual independent variables and total household costs. Independent variables included patient sex, age, household wealth tertile, rural residence, type of health facility and facility management (CHAM or $\mathrm{MoH})$, whether the patient sought care prior to coming to the current facility, the length of the hospital stay, and the distance from the patient's home to the health facility.

Standard diagnostics showed that the primary outcome (household costs) was highly skewed to the right and heteroskedastic (Fig. 1a, b), precluding the use of parametric tests. Generalized linear models (GLMs) were therefore used to analyse cost data while taking into account the non-normal distribution of the data [30]. The distribution
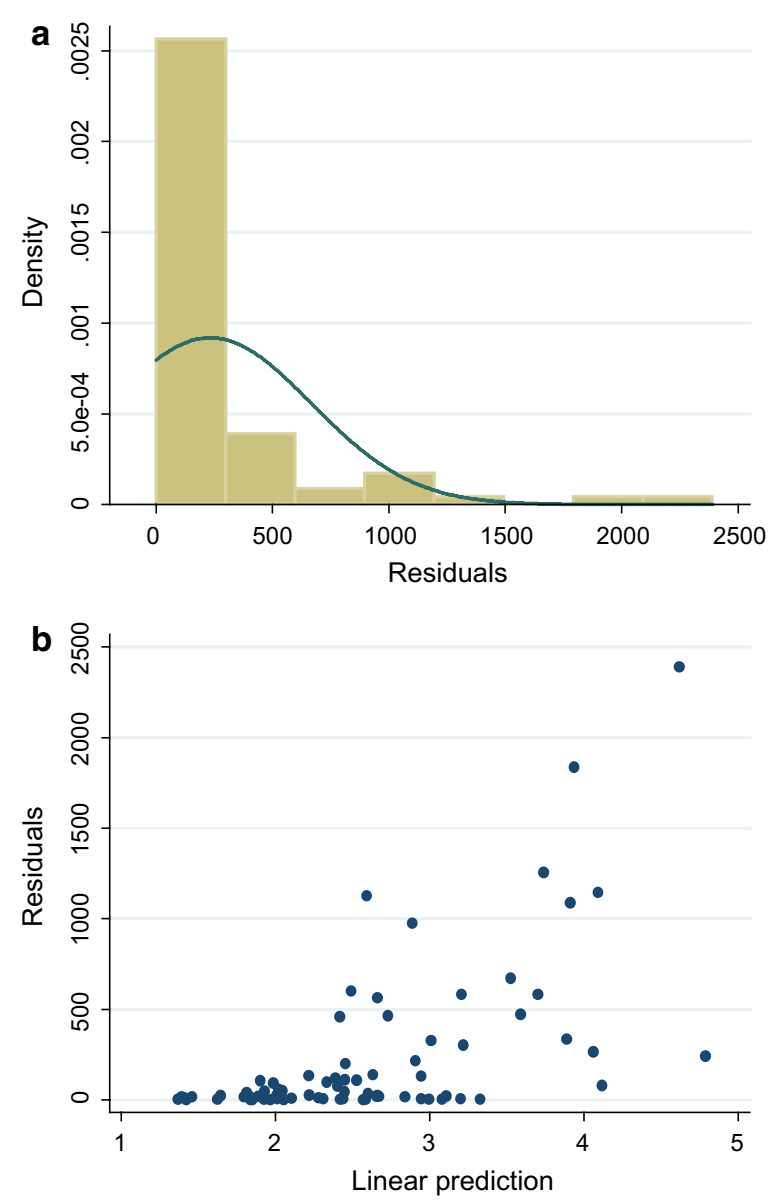

Fig.s 1 Regression diagnostics for ordinary least squares on household costs (\$). a Distribution of squared residuals. b Scatter of residuals vs. fitted values, showing increasing variations of points as predicted values increase, suggestive of heteroskedasticity
(F) of the dependent variable and the link function (g) describing how independent variables are functionally related to the dependent variable need to be specified in GLMs [31]. To select appropriate distribution and link functions for the primary study outcome, the modified Parks test was used [32], and a log link with Gamma distribution provided the best fit for the data.

The empirical GLM took the form:

$$
g\left(\mu_{i}\right)=\beta_{0}+\beta_{1 \mathrm{i}} X_{i}, y_{i} \sim F
$$

where $\mu_{i}$ denotes the dependent variable of interest (household costs) for every unit (case treated for inpatient malaria), and $X_{i}$ is a vector of independent factors known or presumed to influence the household costs as outlined above. Two models were run; in the full model, all independent factors were included. In the restricted model, a backward stepwise regression was used, beginning with the full model, and retaining only independent factors with corresponding p values $<0.05$. Robust standard errors clustered at the health facility level were generated. The exponential of coefficients $\left(\beta_{\mathrm{i}}\right)$ in GLMs with a log link are interpreted as the ratio of arithmetic means between groups [30].

\section{Ethical considerations}

Ethical approval from both the US centers for disease control and prevention institutional review board (Atlanta, GA USA) and the university of Malawi college of medicine research and ethics committee (Blantyre, Malawi) was granted prior to study implementation. Written informed consent was obtained from patients 18 years and older, or caregivers for incapacitated patients or patients less than 18 years prior to data collection. Patients aged 7-18 years and not incapacitated were asked to provide written assent as well.

\section{Results}

\section{Characteristics of survey respondents}

Out of 100 patients who were eligible to provide cost information, $80(80 \%)$ provided cost information about their current malaria episode and were included in this analysis (Table 1 ). The 20 patients who did not provide cost information were significantly older [mean 30.7; median 27.5, interquartile range (IQR) 4.5-55.5] than those who did provide cost information $(p=0.01)$, but otherwise did not differ based on demographics, illness, and treatment seeking characteristics. Among patients who did provide cost information, the mean age was 13 years (median 4.9; IQR 2-17.5); 31 (39\%) of the patients were under 5 years old, 46 (57\%) were 5 years or older, and 3 (4\%) were of unknown age. Approximately half $(54 \%)$ were female, and the majority (94\%) lived in rural areas. 
Table 1 Characteristics of patients who provided information about household costs for management of malaria episodes resulting in hospitalization in Malawi, by age group, $2012(\mathrm{~N}=80)$

\begin{tabular}{|c|c|c|c|}
\hline & $\begin{array}{l}<5 \text { years } \\
n=31(\%)\end{array}$ & $\begin{array}{l}\geq 5 \text { years } \\
n=46(\%)\end{array}$ & $\begin{array}{l}\text { Total } \% \\
\mathrm{n}=\mathbf{8 0}\end{array}$ \\
\hline Age in years, median (IQR) & $1.6(1.0,2.7)$ & $12.0(5.9,30.6)$ & $4.9(2.0,17.5)$ \\
\hline \multicolumn{4}{|l|}{ Sex } \\
\hline Male & $14(45.7)$ & $22(47.8)$ & $37(46.3)$ \\
\hline Female & $17(54.8)$ & $24(31.2)$ & $43(53.8)$ \\
\hline \multicolumn{4}{|l|}{ Residence } \\
\hline Rural & $30(96.8)$ & $42(91.3)$ & $5(6.25)$ \\
\hline Urban/small town & $1(3.22)$ & $4(8.7)$ & $75(93.8)$ \\
\hline \multicolumn{4}{|l|}{ Wealth tertile } \\
\hline Least poor & $5(16.1)$ & $20(43.5)$ & $26(32.5)$ \\
\hline Middle & $11(35.5)$ & $15(32.6)$ & $26(32.5)$ \\
\hline Poorest & $15(48.4)$ & $11(23.9)$ & $28(35.0)$ \\
\hline \multicolumn{4}{|l|}{ Health facility management } \\
\hline $\mathrm{MoH}$ & $20(64.5)$ & $24(52.2)$ & $46(57.5)$ \\
\hline CHAM & $11(35.5)$ & $22(47.8)$ & $34(42.5)$ \\
\hline \multicolumn{4}{|l|}{ Health facility type } \\
\hline District/central & $16(51.6)$ & $18(39.1)$ & $36(45.0)$ \\
\hline Other hospital type & $10(32.3)$ & $22(47.8)$ & $33(41.3)$ \\
\hline Community/rural & $5(16.1)$ & $6(13.1)$ & $11(13.8)$ \\
\hline Days in hospital, median (IQR) & $1.4(0.7,2.1)$ & $2.0(0.6,2.7)$ & $1.5(0.6,2.6)$ \\
\hline Days of illness, median (IQR) & $1.8(0.7,3.5)$ & $3.5(1.3,7.5)$ & $2.8(0.9,5.8)$ \\
\hline \multicolumn{4}{|l|}{ Sought care prior } \\
\hline Yes & $19(61.3)$ & $40(87.0)$ & $60(75.0)$ \\
\hline No & $12(38.7)$ & $6(13.0)$ & $20(25.0)$ \\
\hline \multicolumn{4}{|l|}{ Distance, home to facility (km) } \\
\hline$<5$ & $13(41.9)$ & $23(50.0)$ & $36(45.0)$ \\
\hline$\geq 5$ & $18(58.1)$ & $23(50.0)$ & $44(55.0)$ \\
\hline Travel time to and from facility in days, median (IQR) & $0.14(0.1,0.2)$ & $0.16(0.0,0.2)$ & $0.15(0.1,0.2)$ \\
\hline
\end{tabular}

CHAM Christian Health Association of Malawi, $\mathrm{MoH}$ Ministry of Health, IQR interquartile range

Patients reported being ill for a mean of 7.4 days (median 2.8; IQR 0.9-5.8) prior to seeking care at the current facility, and spent a mean of 2.5 days admitted to the health facility (median 1.5; IQR 0.0-12.0). A total of $60(75 \%)$ patients had sought care at another facility prior to admission at the study facility, and 26 (32.5\%) patients were discharged on the day of the study. Patients lived a mean distance of 10.2 kilometres (median 4.4; IQR 1.410.0) away from the health facility, and more than half (55\%) lived 5 or more kilometres away. Patients travelled for an average of 0.2 days (median 0.1 ; IQR $0.0-1.7$ ) to and from the facility in order to access care.

\section{Total household costs}

The mean household cost of malaria episodes resulting in inpatient admission, including direct and indirect costs, was \$17.48 (median \$9.78; IQR \$3.66-\$23.56). In bivariate analysis (Table 2), household costs averaged $\$ 23.43$ (median \$17.00; IQR \$7.97-\$28.74) for patients who visited CHAM facilities compared to $\$ 13.09$ (median $\$ 6.59$; IQR \$2.08-\$14.99) for those who visited $\mathrm{MoH}$ facilities $(p=0.06)$. Children under 5 years incurred a mean total cost of $\$ 9.74$ (median \$7.15; IQR \$2.09-\$13.09) compared to $\$ 22.86$ (median \$14.23; IQR \$4.94-\$33.57) for those 5 years and older $(p<0.01)$. Patients from the least poor wealth tertile had higher mean costs at $\$ 28.06$ (median \$17.00; IQR \$6.49-\$42.62) than those in the middle tertile (mean \$9.82; median \$7.58; IQR \$2.13$\$ 13.34$ ) and poorest tertile (mean $\$ 14.39$; median $\$ 8.05$; IQR \$2.20-\$23.56) ( $p<0.01)$. Household wealth was not associated with the likelihood of patients attending a $\mathrm{CHAM}$ vs. $\mathrm{MoH}$ facility $(p=0.14)$.

Patients from rural residences incurred lower costs at a mean of \$15.03 (median \$8.60; IQR \$3.02-\$19.47) compared to $\$ 50.68$ (median $\$ 26.57$; IQR $\$ 22.04-\$ 63.10$ ) for patients from urban or small town residences $(p<0.01)$. 
Table 2 Bivariate predictors of total household cost for the management of malaria episodes resulting in hospitalization in Malawi, $2012(\mathrm{~N}=\mathbf{8 0})$

\begin{tabular}{|c|c|c|c|c|c|c|}
\hline & $n$ & Mean & Median & IQR & & $p$ value \\
\hline Total costs & 80 & $\$ 17.48$ & $\$ 9.78$ & $\$ 3.66$ & $\$ 23.56$ & \\
\hline \multicolumn{7}{|l|}{ Facility ownership } \\
\hline CHAM & 34 & $\$ 23.43$ & $\$ 17.00$ & $\$ 7.97$ & $\$ 28.74$ & \multirow[t]{2}{*}{0.06} \\
\hline $\mathrm{MOH}^{\mathrm{r}}$ & 46 & $\$ 13.09$ & $\$ 6.59$ & $\$ 2.08$ & $\$ 14.99$ & \\
\hline \multicolumn{7}{|l|}{ Facility type } \\
\hline District hospital & 36 & $\$ 13.32$ & $\$ 6.39$ & $\$ 2.01$ & $\$ 13.09$ & \multirow[t]{2}{*}{$<0.01$} \\
\hline Rural/community/other & 11 & $\$ 13.50$ & $\$ 9.30$ & $\$ 4.51$ & $\$ 17.61$ & \\
\hline \multicolumn{7}{|l|}{ Cost by age (years) } \\
\hline$<5$ & 31 & $\$ 9.74$ & $\$ 7.15$ & $\$ 2.09$ & $\$ 13.32$ & \multirow[t]{2}{*}{$<0.01$} \\
\hline$\geq 5^{r}$ & 46 & $\$ 22.86$ & $\$ 14.23$ & $\$ 4.94$ & $\$ 33.57$ & \\
\hline \multicolumn{7}{|l|}{ Sex } \\
\hline Male & 37 & $\$ 13.08$ & $\$ 7.35$ & $\$ 2.03$ & $\$ 16.27$ & \multirow[t]{2}{*}{0.12} \\
\hline Female ${ }^{r}$ & 43 & $\$ 21.27$ & $\$ 13.05$ & $\$ 6.16$ & $\$ 27.71$ & \\
\hline \multicolumn{7}{|l|}{ Wealth tertile } \\
\hline Least poor & 26 & $\$ 28.47$ & $\$ 17.00$ & $\$ 6.49$ & $\$ 42.62$ & \multirow[t]{3}{*}{$<0.01$} \\
\hline Middle & 26 & $\$ 9.82$ & $\$ 7.58$ & $\$ 2.13$ & $\$ 13.34$ & \\
\hline Poorest ${ }^{r}$ & 28 & $\$ 14.39$ & $\$ 8.05$ & $\$ 2.20$ & $\$ 23.56$ & \\
\hline \multicolumn{7}{|l|}{ Duration of hospital stay } \\
\hline Long ( $\geq 2$ days) & 26 & $\$ 24.53$ & $\$ 19.38$ & $\$ 12.67$ & $\$ 30.47$ & \multirow[t]{2}{*}{0.16} \\
\hline Short $(<2 \text { days })^{r}$ & 16 & $\$ 14.76$ & $\$ 6.39$ & $\$ 6.98$ & $\$ 14.23$ & \\
\hline \multicolumn{7}{|l|}{ Sought care prior } \\
\hline Yes & 60 & $\$ 19.00$ & $\$ 9.39$ & $\$ 3.29$ & $\$ 17.00$ & \multirow[t]{2}{*}{0.02} \\
\hline $\mathrm{No}^{r}$ & 20 & $\$ 12.94$ & $\$ 9.78$ & $\$ 3.66$ & $\$ 26.46$ & \\
\hline \multicolumn{7}{|c|}{ Distance from home to HF (km) } \\
\hline$<5$ & 36 & $\$ 15.78$ & $\$ 8.05$ & $\$ 3.29$ & $\$ 17.00$ & \multirow[t]{2}{*}{0.54} \\
\hline$\geq 5^{r}$ & 44 & $\$ 18.88$ & $\$ 13.01$ & $\$ 3.66$ & $\$ 26.46$ & \\
\hline \multicolumn{7}{|l|}{ Residence } \\
\hline Rural & 75 & $\$ 15.27$ & $\$ 8.60$ & $\$ 3.02$ & $\$ 19.47$ & \multirow[t]{2}{*}{$<0.01$} \\
\hline Urban/small town ${ }^{r}$ & 5 & $\$ 50.68$ & $\$ 26.57$ & $\$ 22.04$ & $\$ 63.10$ & \\
\hline
\end{tabular}

$\mathrm{MoH}$ Ministry of Health, CHAM Christian Health Association of Malawi, HF health facility

${ }^{r}$ Reference

Patients who had sought prior care for their present malaria episode had significantly higher mean costs at \$19.00 (median \$9.39; IQR \$3.29-\$17.00) compared to $\$ 12.94$ (median $\$ 9.78$, IQR $\$ 3.66-26.46$ ) for patients who had not sought prior care $(p=0.02)$. Mean household costs were $\$ 11.56$ per night admitted (median $\$ 6.78$; IQR \$3.42-\$12.09). Mean costs for patients who were discharged the day of the interview were $\$ 13.89$ (median \$13.89; IQR \$6.68-\$16.95), compared to \$16.05 (median $\$ 5.85$; IQR \$1.01-\$16.83) for patients who were not discharged the day of the interview $(p=0.62)$.

Multivariate GLM regression was used to determine patient and facility characteristics associated with total household costs per malaria episode (Table 3). In the restricted model, and controlling for all other variables, household costs for management of malaria illness resulting in admission in CHAM facilities were $52 \%$ higher than at $\mathrm{MoH}$ facilities $(p<0.01)$. Household costs for children under 5 years were $40 \%$ lower than for patients 5 years and older $(p<0.01)$. Household costs were $40 \%$ lower for patients that lived $<5 \mathrm{~km}$ away from the health facility compared to those who lived $5 \mathrm{~km}$ or greater away $(p<0.01)$. Each day in the hospital was associated with a $2 \%$ increase in overall household costs $(p=0.03)$. Costs for households in the wealthiest tertile were $82 \%$ higher than costs for households in the middle and poorest tertiles $(p<0.01)$.

\section{Direct household costs}

The mean direct cost incurred by patients admitted for malaria episodes was $\$ 7.59$ (median $\$ 7.59$; IQR \$0.91\$9.51) (Table 4). Costs differed significantly by facility 
Table 3 GLM regression results for the predictors of the total household cost of malaria episodes resulting in hospitalization in Malawi, $2012(\mathrm{~N}=\mathbf{8 0})$

\begin{tabular}{|c|c|c|c|c|c|c|}
\hline & Coefficient ( $\beta$ ) & $\begin{array}{l}\text { Robust standard } \\
\text { error }\end{array}$ & $\begin{array}{l}\text { Ratio of arithmetic } \\
\text { means }^{\mathrm{a}}\end{array}$ & \multicolumn{2}{|c|}{$\begin{array}{l}95 \% \text { confidence } \\
\text { interval }\end{array}$} & $p$ value \\
\hline \multicolumn{7}{|l|}{ Full model } \\
\hline Sex (female vs. male) & 0.48 & 0.47 & 1.62 & 0.65 & 4.06 & 0.302 \\
\hline Age $<5$ years vs. $\geq 5$ years & -0.51 & 0.08 & 0.60 & 0.51 & 0.71 & $<0.01$ \\
\hline Wealth tertile, middle vs. least poor and poorest & -0.54 & -4.18 & 0.59 & 0.46 & 0.75 & $<0.01$ \\
\hline Wealth tertile, poorest vs. least poor and middle & -0.45 & -2.58 & 0.64 & 0.45 & 0.90 & 0.01 \\
\hline CHAM vs. MoH & 0.40 & 0.05 & 1.49 & 1.35 & 1.65 & $<0.01$ \\
\hline Rural vs. urban residence & -0.20 & 0.27 & 0.82 & 0.48 & 1.38 & 0.456 \\
\hline Days in hospital & 0.02 & 0.00 & 1.02 & 1.01 & 1.03 & $<0.01$ \\
\hline \multicolumn{7}{|l|}{ Restricted model } \\
\hline Age $<5$ years vs. $\geq 5$ years & -0.51 & 0.09 & 0.60 & 0.51 & 0.71 & $<0.01$ \\
\hline Wealth tertile, least poor vs. middle and poorest & 0.60 & 0.08 & 1.82 & 1.57 & 2.11 & $<0.01$ \\
\hline CHAM vs. MoH & 0.42 & 0.06 & 1.52 & 1.36 & 1.70 & $<0.01$ \\
\hline Days in hospital & 0.02 & 0.01 & 1.02 & 1.00 & 1.04 & 0.03 \\
\hline Distance to health facility $(<5 \mathrm{~km}$ vs. $\geq 5 \mathrm{~km})$ & -0.50 & 0.05 & 0.61 & 0.55 & 0.67 & $<0.01$ \\
\hline
\end{tabular}

MoH Ministry of Health, CHAM Christian Health Association of Malawi

a Exponentiated coefficient $\beta_{;}$; multiplicative effect of variable on total household cost

Table 4 Direct household costs in USD for management of malaria episodes resulting in hospitalization at health facilities in Malawi, 2012 ( $N=80)$

\begin{tabular}{lllll}
\hline & Mean & Median & IQR & \\
\hline Total direct costs & $\$ 7.59$ & $\$ 3.12$ & $\$ 0.91$ & $\$ 9.51$ \\
Direct medical costs & $\$ 2.39$ & $\$ 0.00$ & $\$ 0.00$ & $\$ 2.62$ \\
Medications & $\$ 2.38$ & $\$ 0.00$ & $\$ 0.00$ & $\$ 2.62$ \\
Direct non-medical costs & $\$ 5.20$ & $\$ 1.89$ & $\$ 0.11$ & $\$ 6.22$ \\
Travel to and from HF & $\$ 3.70$ & $\$ 1.04$ & $\$ 0.00$ & $\$ 3.23$ \\
Accommodation & $\$ 0.05$ & $\$ 0.00$ & $\$ 0.00$ & $\$ 0.00$ \\
Meals & $\$ 4.42$ & $\$ 1.94$ & $\$ 0.61$ & $\$ 5.81$ \\
\hline
\end{tabular}

$H F$ health facility, IQR interquartile range

management, averaging \$5.59 (median \$2.15; IQR \$0.69$\$ 6.40)$ at $\mathrm{MoH}$ health facilities compared to $\$ 10.28$ at CHAM facilities (median \$4.75; IQR \$1.65-\$13.67) $(p<0.05)$ (Table 5). Direct costs for patients under 5 years (mean \$5.30; median \$2.15; IQR \$1.29-\$7.50) were not significantly different from those for patients 5 years and over (mean \$9.43; median \$4.02; IQR \$0.64-\$13.87) $(p=0.06)$, and no other predictors were found to be significant. Direct medical costs averaged \$2.39 (median \$0.00; IQR \$0.00-\$2.62), with medications accounting for almost all direct medical costs (mean $\$ 2.38$; median \$0.00; IQR \$0.00-\$2.62). These direct medical costs differed significantly by facility ownership, averaging $\$ 1.06$ (median \$0.00; IQR \$0.00-\$0.82) at $\mathrm{MoH}$ health facilities compared to $\$ 4.19$ (median $\$ 2.13$; IQR \$0.00-\$5.85) at CHAM facilities $(p=0.01)$. Direct non-medical costs averaged \$5.20 (median \$1.89; IQR \$0.11-\$6.22); these averaged \$4.54 (median \$1.92; IQR \$0.32-\$4.94) for $\mathrm{MoH}$ facilities and $\$ 6.09$ (median $\$ 1.83$; IQR $\$ 0.00-$ $\$ 6.04)$ at CHAM facilities $(p=0.42)$. Meals and travel accounted for the largest proportion of direct non-medical costs and were the two most substantial contributors to overall direct costs, but were not significantly different by CHAM vs. MoH management type.

\section{Indirect costs}

Overall, each malaria episode resulted in a mean loss of 8.5 productive days (median 4.1; IQR $0.0-11.1$ ), including lost productive days for both patients and their caregivers. This was associated with a mean lost productivity cost of \$9.90 per episode (median \$4.74; IQR \$0.00-\$12.84) (Table 6). While patients under 14 did not themselves incur any indirect costs due to lost days of work, the productivity lost by their accompanying adult caregivers was calculated for their illness episode. When caregiver time is included, total lost productivity time for patients under 14 years was 4.1 productive days (median 0.0; IQR 0.06.2), which was considerably smaller than 19.6 days for patients 14 years and older (median 13.9; IQR 7.1-20.3). This was associated with an average lost productivity cost of \$4.73 (median \$0.00; IQR \$0.00-\$12.84) for patients under 14 years compared to $\$ 22.70$ (median $\$ 16.08$; IQR \$8.23-\$23.49) for patients 14 years and older.

When associated caregiver costs are excluded, patients 14 years and older lost an average of 10.4 productive days 
Table 5 Direct household costs in USD for management of malaria episodes resulting in hospitalization at health facilities in Malawi, by facility type and age, $2012(\mathrm{~N}=80)$

\begin{tabular}{|c|c|c|c|c|c|c|c|c|c|}
\hline & \multicolumn{4}{|l|}{$\mathrm{MoH}^{\mathrm{a}}$} & \multicolumn{4}{|l|}{ CHAM $^{b}$} & \multirow[t]{2}{*}{$p$ value } \\
\hline & Mean & Median & IQR & & Mean & Median & IQR & & \\
\hline Total direct costs & $\$ 5.59$ & $\$ 2.15$ & $\$ 0.69$ & $\$ 6.40$ & $\$ 10.28$ & $\$ 4.75$ & $\$ 1.65$ & $\$ 13.67$ & 0.05 \\
\hline Direct medical costs & $\$ 1.06$ & $\$ 0.00$ & $\$ 0.00$ & $\$ 0.82$ & $\$ 4.19$ & $\$ 2.13$ & $\$ 0.00$ & $\$ 5.85$ & 0.01 \\
\hline Medications & $\$ 1.06$ & $\$ 0.00$ & $\$ 0.00$ & $\$ 0.82$ & $\$ 4.16$ & $\$ 1.95$ & $\$ 0.00$ & $\$ 5.85$ & 0.01 \\
\hline Direct non-medical costs & $\$ 4.54$ & $\$ 1.92$ & $\$ 0.32$ & $\$ 4.94$ & $\$ 6.09$ & $\$ 1.83$ & $\$ 0.00$ & $\$ 6.04$ & 0.42 \\
\hline Travel to and from HF & $\$ 3.29$ & $\$ 1.65$ & $\$ 0.00$ & $\$ 3.06$ & $\$ 4.26$ & $\$ 0.36$ & $\$ 0.00$ & $\$ 4.02$ & 0.53 \\
\hline Accommodation & $\$ 0.09$ & $\$ 0.00$ & $\$ 0.00$ & $\$ 0.00$ & $\$ 0.00$ & $\$ 0.00$ & $\$ 0.00$ & $\$ 0.00$ & 0.31 \\
\hline \multirow[t]{2}{*}{ Meals } & $\$ 3.80$ & $\$ 1.65$ & $\$ 0.61$ & $\$ 4.02$ & $\$ 5.20$ & $\$ 2.20$ & $\$ 0.37$ & $\$ 5.73$ & 0.42 \\
\hline & \multicolumn{4}{|c|}{ Patients $<5$ years ${ }^{c}$} & \multicolumn{4}{|c|}{ Patients $\geq 5$ years $^{d}$} & \\
\hline Total direct costs & $\$ 5.30$ & $\$ 2.15$ & $\$ 1.29$ & $\$ 7.50$ & $\$ 9.43$ & $\$ 4.02$ & $\$ 0.64$ & $\$ 13.87$ & 0.06 \\
\hline Direct medical costs & $\$ 2.00$ & $\$ 0.00$ & $\$ 0.00$ & $\$ 2.13$ & $\$ 2.79$ & $\$ 0.00$ & $\$ 0.00$ & $\$ 3.17$ & 0.40 \\
\hline Medications & $\$ 2.00$ & $\$ 0.00$ & $\$ 0.00$ & $\$ 2.13$ & $\$ 2.79$ & $\$ 0.00$ & $\$ 0.00$ & $\$ 3.17$ & 0.42 \\
\hline Direct non-medical costs & $\$ 3.30$ & $\$ 1.56$ & $\$ 0.21$ & $\$ 4.30$ & $\$ 6.63$ & $\$ 2.10$ & $\$ 0.00$ & $\$ 6.40$ & 0.06 \\
\hline Travel to and from HF & $\$ 2.65$ & $\$ 0.82$ & $\$ 0.00$ & $\$ 2.74$ & $\$ 4.58$ & $\$ 1.65$ & $\$ 0.00$ & $\$ 3.84$ & 0.22 \\
\hline Accommodation & $\$ 0.00$ & $\$ 0.00$ & $\$ 0.00$ & $\$ 0.00$ & $\$ 0.05$ & $\$ 0.00$ & $\$ 0.00$ & $\$ 0.54$ & 0.39 \\
\hline Meals & $\$ 2.52$ & $\$ 0.62$ & $\$ 0.55$ & $\$ 2.56$ & $\$ 5.52$ & $\$ 2.12$ & $\$ 0.98$ & $\$ 6.86$ & 0.13 \\
\hline
\end{tabular}

$\mathrm{MoH}$ Ministry of Health, CHAM Christian Health Association of Malawi, HF health facility, IQR interquartile range

${ }^{\mathrm{a}} \mathrm{N}=46,{ }^{\mathrm{b}} \mathrm{N}=31,{ }^{\mathrm{c}} \mathrm{N}=31,{ }^{\mathrm{d}} \mathrm{N}=46$

Table 6 Indirect household costs in USD for the management of malaria episodes resulting in hospitalization in Malawi, $2012(\mathrm{~N}=80)$

\begin{tabular}{|c|c|c|c|c|c|c|c|c|c|}
\hline & \multicolumn{5}{|c|}{$\begin{array}{l}\text { Productive days lost due to malaria epi- } \\
\text { sode }\end{array}$} & \multicolumn{4}{|c|}{ Associated productivity costs } \\
\hline & $\mathbf{n}$ & Mean & Median & IQR & & Mean & Median & IQR & \\
\hline Total indirect costs (combined patient and caregiver costs) & 80 & 8.5 & 4.1 & 0.0 & 11.1 & $\$ 9.90$ & $\$ 4.74$ & $\$ 0.00$ & $\$ 12.84$ \\
\hline Total indirect costs $<14$ years & 57 & 4.1 & 0.0 & 0.0 & 6.2 & $\$ 4.73$ & $\$ 0.00$ & $\$ 0.00$ & $\$ 7.13$ \\
\hline Total indirect costs $\geq 14$ years & 23 & 19.6 & 13.9 & 7.1 & 20.3 & $\$ 22.70$ & $\$ 16.08$ & $\$ 8.23$ & $\$ 23.49$ \\
\hline Lost productivity for patients $\geq 14$ years & 23 & 10.4 & 6.1 & 5.2 & 9.2 & $\$ 15.89$ & $\$ 8.31$ & $\$ 5.97$ & $\$ 16.50$ \\
\hline Lost productivity prior to the current admission ${ }^{a}$ & 23 & 12.0 & 6.5 & 2.9 & 12.2 & $\$ 13.97$ & $\$ 7.54$ & $\$ 3.33$ & $\$ 14.11$ \\
\hline Lost productivity during current admission ${ }^{b}$ & 23 & 1.7 & 0.7 & 0.1 & 2.4 & $\$ 1.92$ & $\$ 0.78$ & $\$ 0.13$ & $\$ 2.79$ \\
\hline Lost productivity for caregivers & 80 & 9.2 & 7.1 & 4.3 & 11.1 & $\$ 10.65$ & $\$ 8.27$ & $\$ 5.03$ & $\$ 12.84$ \\
\hline Lost productivity prior to the current admission ${ }^{a}$ & 80 & 5.6 & 3.4 & 1.0 & 7.0 & $\$ 6.47$ & $\$ 3.98$ & $\$ 1.16$ & $\$ 8.12$ \\
\hline Lost productivity during current admission ${ }^{b}$ & 80 & 3.6 & 3.1 & 2.1 & 4.4 & $\$ 4.19$ & $\$ 3.58$ & $\$ 2.40$ & $\$ 5.13$ \\
\hline Lost productivity for caregivers for patients $<5$ years & 31 & 7.9 & 6.1 & 4.2 & 8.4 & $\$ 9.18$ & $\$ 7.11$ & $\$ 4.81$ & $\$ 9.76$ \\
\hline Lost productivity prior to the current admission ${ }^{a}$ & 31 & 4.6 & 2.8 & 1.4 & 5.1 & $\$ 5.34$ & $\$ 3.29$ & $\$ 1.59$ & $\$ 5.94$ \\
\hline Lost productivity during current admission ${ }^{b}$ & 31 & 3.3 & 3.1 & 2.1 & 4.2 & $\$ 3.84$ & $\$ 3.63$ & $\$ 2.49$ & $\$ 4.82$ \\
\hline Lost productivity for caregivers for patients $\geq 5$ years & 46 & 9.9 & 8.3 & 5.0 & 11.7 & $\$ 11.48$ & $\$ 9.68$ & $\$ 5.82$ & $\$ 13.56$ \\
\hline Lost productivity prior to the current admission ${ }^{a}$ & 46 & 6.3 & 3.5 & 1.0 & 7.8 & $\$ 7.33$ & $\$ 4.06$ & $\$ 1.16$ & $\$ 8.99$ \\
\hline Lost productivity during current admission ${ }^{b}$ & 46 & 3.6 & 3.1 & 1.5 & 5.6 & $\$ 4.15$ & $\$ 3.55$ & $\$ 1.79$ & $\$ 6.47$ \\
\hline \multicolumn{10}{|l|}{ Total indirect costs by wealth index } \\
\hline Least poor & 26 & 16.5 & 8.3 & 2.7 & 14.3 & $\$ 16.67$ & $\$ 8.15$ & $\$ 0.00$ & $\$ 17.66$ \\
\hline Middle & 26 & 7.0 & 6.1 & 3.1 & 9.7 & $\$ 4.88$ & $\$ 3.53$ & $\$ 0.00$ & $\$ 8.29$ \\
\hline Poorest & 28 & 9.0 & 6.0 & 2.1 & 10.2 & $\$ 8.27$ & $\$ 3.87$ & $\$ 0.00$ & $\$ 9.43$ \\
\hline
\end{tabular}

\footnotetext{
a Time spent ill or providing care to sick patients prior to seeking care for current malaria episode for patients and caregivers, respectively
}

b Sum of time spent travelling to and from facility, waiting for admittance, and days spent in care 
(median 6.1; IQR 5.2-9.2), which was associated with an average lost productivity cost of $\$ 15.89$ (median $\$ 8.31$; IQR \$5.97-\$16.50). Likewise, excluding patient costs, caregivers alone lost a mean of 9.2 days (median 7.1; IQR 4.3-11.1) caring for and accompanying sick patients, with an associated lost productivity cost of $\$ 10.65$ (median \$8.27; IQR \$5.03-\$12.84). Caregivers accompanying patients under 5 years lost 7.9 productive days (median 6.1; IQR 4.2-8.4), compared to 9.9 productive days lost (median 8.3; IQR 5.0-11.7) for those accompanying patients 5 years and older $(p=0.26)$. Households in the least poor wealth index tertile lost an average of 16.5 productive days (median 8.3; IQR 2.7-14.3), compared to 7.0 days (median 6.1; IQR 3.1-9.7) for households in the middle wealth tertile and 9.0 days (median 6.0; IQR $2.1-10.2)$ for households in the poorest tertile $(p=0.07)$.

\section{Discussion}

Despite policies aimed at providing free healthcare through the formal healthcare system [22], households in Malawi still incurred important direct and indirect costs to manage malaria episodes that resulted in admission. The average total cost of $\$ 17.48$ per episode represents more than a week's worth of income for most Malawian families; such a cost could be catastrophic to many families. Although the total costs were about $50 \%$ lower for patients treated at government facilities than the non-profit CHAM facilities, total costs at government facilities were nevertheless substantial at $\$ 12.70$ per episode. While healthcare subsidies appear to be having an important effect in limiting some of the direct medical costs, relatively high medication costs, meals, and travel costs still resulted in substantial overall direct household costs at an average of $\$ 7.59$ per episode. Indirect costs accounted for an additional $\$ 9.90$ per episode and are likely to further compound malaria's economic burden, particularly on less wealthy households, and will be more difficult to influence with current government policies.

Management of malaria episodes that result in admission poses a much greater economic strain on Malawian households than uncomplicated, outpatient malaria episodes. Studies in Malawi have reported direct household costs for uncomplicated malaria ranging from $\$ 1.28$ to $\$ 5.52$ in constant 2012 dollars $[16,17,19]$. These costs are substantially lower than the $\$ 7.59$ in direct household costs that patients with a malaria episode resulting in hospitalization incurred. While inpatient malaria episodes might intuitively be expected to be more costly than outpatient episodes, relatively few previous household cost studies have examined inpatient malaria in order to quantify this difference. Additionally, while costs were highest among households in the highest wealth tertile, they remained important for households in the middle and poorest wealth tertiles at $\$ 9.82$ and $\$ 14.32$, respectively. Because of this, the economic burden of malaria is likely to be relatively high for the lowest income households, as has been shown elsewhere [9, 17]. This information may inform policy efforts to further subsidize the cost of inpatient malaria management and reduce the burden of severe malaria on low income households.

The high direct costs for management of malaria episodes resulting in hospitalization in Malawi are similar to those observed in Mozambique, Ghana, and Uganda for inpatient management of malaria episodes [9, 10,33], and less than reported for severe malaria patients in Sudan where direct household costs averaged \$17.20 (\$22.30 in constant 2012 US dollars) for the management of severe malaria episodes [11]. This may be in part due to differences in study design; the Sudan study only reviewed costs for patients hospitalized and treated for severe or complicated malaria, whereas this study included all hospitalized patients who received anti-malarial treatment, and did not discriminate between patients with different malaria diagnoses or severity. Further studies in Malawi should prioritize assessment of household cost among patients hospitalized with a severe malaria diagnosis, as these costs are likely to be higher than those observed in this study and may be particularly catastrophic to low income households.

Patients who visited CHAM-owned facilities incurred higher costs than those who visited $\mathrm{MoH}$ facilities. Although CHAM facilities receive some government subsidies for their operations [2], they charge nominal service fees to cover operational costs, which results in increased direct household costs. Additionally, central medical store stock-outs sometimes force CHAM facilities to procure essential medications locally at commercial prices, the costs of which may be passed on to patients [34]. Indeed, patients in this study paid an average of $\$ 4.16$ for medications at CHAM facilities compared to only $\$ 1.06$ at $\mathrm{MoH}$ facilities. This probably reflects higher costs per medication, as there were no significant differences between the type or average number of medications received at $\mathrm{CHAM}$ vs. MoH facilities.

The apparently higher cost of medication at CHAM facilities represents an important avenue for policy intervention; additional governmental subsidies for antimalarial medications at CHAM facilities and increased attention to supply chain issues could reduce direct medical costs for patients visiting CHAM facilities. This is especially important given that family wealth status was not a predictor of which type of facility patients visited, so poorer families who visit CHAM facilities 
could benefit substantially from such policies. Additionally, continued medication subsidies should ensure that medications remain affordable at both $\mathrm{CHAM}$ and $\mathrm{MoH}$ facilities.

Despite government efforts to expand healthcare access in rural areas of Malawi [22], increasing distance from a health facility is still associated with higher care seeking costs. Travel costs accounted for an average of $48 \%$ of direct household expenditures, and households that lived less than $5 \mathrm{~km}$ away from the health facility incurred a $40 \%$ lower cost per episode compared to those who lived $5 \mathrm{~km}$ or more away. Previous studies have shown that increased costs limit treatment seeking behavior in harder to reach households (those more than $5 \mathrm{~km}$ away from health facilities) $[19,33]$, and may account for substantial delays in accessing care [35]. Distance to a health facility and associated travel costs may, therefore, constitute a major financial burden for low income families as well as a significant barrier to prompt care-seeking, which could in turn contribute to negative health outcomes.

This study has several limitations. Because it was conducted as part of a larger study, it was not explicitly powered to examine cost outcomes. The retrospective study design introduced the possibility of recall bias, as patients may not have accurately remembered prices incurred for malaria treatment at previous health facilities, although cost information collected was limited to the current malaria episode in order to minimize recall bias. Additionally, the lost costs associated with school fees for absent days of school were not included in the indirect cost estimates, as data on school fees were not collected. Thus, the costs presented here may underestimate the true household costs of inpatient malaria episodes.

Complete malaria episode information was only available for patients who were discharged the day of the survey. Thus, the cost estimates presented here may underestimate the true overall costs. However, total costs for patients who were discharged the day of the interview compared to those who were not yet discharged were not significantly different. Furthermore, patients were not followed longitudinally. Thus, even for patients discharged the day of the survey, information on after-care, including productive time lost by patients and their caregivers during recovery, and any recrudescence and related costs were not collected. Again, this likely resulted in underestimation of overall household costs associated with malaria episodes. Finally, the findings may not be generalizable to other settings where malaria care subsidies and cost drivers vary substantially.

In settings such as Malawi where health care is heavily subsidized but direct costs remain relatively high, policy efforts to address both medical and non-medical drivers of these costs are crucial. Direct non-medical household costs may be mitigated by subsidizing meals and travel for families under a certain income level through the use of cash transfers or establishing health equity funds. Community health insurance schemes may also address the cost of care-seeking for acute febrile illness episodes. Meanwhile government subsidies should be continued and strengthened to ensure medications, consultations, and other direct medical costs remain affordable at both $\mathrm{CHAM}$ and $\mathrm{MoH}$ facilities. This is especially important given that the costs of inpatient malaria treatment might otherwise be catastrophic for the poorest families, and out of pocket costs are a major barrier to malaria care seeking among poorer households [36]. With $71 \%$ of the population of Malawi living below the poverty level, such policies could help reduce the disproportionate economic burden of malaria care on low-income households, which could in turn encourage prompt care seeking [15]. As delayed care is associated with more severe disease and poorer outcomes [37], this could reduce morbidity and mortality associated with malaria. Additional subsidies for low-income patients who visit CHAM-owned facilities may also reduce the disproportionate economic burden of malaria on poorer families.

Indirect costs may be addressed through continued malaria prevention and education efforts. With more than 3 million malaria cases every year in Malawi, the economic costs due to productive days lost for patients and their caregivers are staggering, making prevention campaigns a good investment both for public health and economic growth $[1,38]$. Expanding community health worker programs and enhanced communication and education efforts may also limit costs through encouraging patients to seek care earlier in their malaria episode when care is likely to be more effective, leading to shorter duration of care and better outcomes [37]. Ultimately, prevention of malaria episodes remains the best means to avoid these costs.

\section{Conclusion}

The findings of this study contribute to the evidence highlighting the substantial economic burden of malaria episodes resulting in hospitalization on households. While direct expenditures are an important component of household costs, indirect costs due to lost productivity magnify the economic burden of inpatient malaria management on families, and costs were notably higher for patients from hard-to-reach households and for those who visited CHAM compared to MoH facilities. As perceived and actual costs of care are important dimensions of access, minimizing these costs is crucial to protect households from potentially catastrophic health expenditures, and ensure that all patients receive prompt and effective care. 


\section{Authors' contributions}

JC, MBH, WD, ML, JS, DA, KAL, DPM and JN contributed to study design. AS, MS, and JN supported development of data collection tools. JC, MBH, AB, MS, $A C$, and DM oversaw data collection and data entry. $I H, J C$, and JN analysed the data. $I H$ and JN drafted the manuscript. JG, MBH, JC, KAL, MS, ML, DM, AC, DA and WD edited the manuscript. All authors read and approved the final manuscript.

\section{Author details \\ ${ }^{1}$ Malaria Branch, Division of Parasitic Diseases and Malaria, Center for Global Health, Centers for Disease Control and Prevention, Atlanta, GA, USA. ${ }^{2}$ Malaria Alert Center, Malawi College of Medicine, Blantyre, Malawi. ${ }^{3}$ National Malaria Control Programme, Malawi Ministry of Health, Lilongwe, Malawi. ${ }^{4}$ World Health Organization, Lilongwe, Malawi.}

\section{Acknowledgements}

The authors gratefully acknowledge Dr. Deborah McFarland for providing subject matter expertise and reviewing the manuscript, and Mr. Ryan Wiegand for providing statistical advice. The authors extend their thanks as well to the patients, healthcare providers, and health facilities that participated in the study, as well as the data collectors and colleagues who supported the implementation of this study.

\section{Competing interests}

The authors declare that they have no competing interests.

\section{Availability of data and materials}

The datasets are available from the corresponding author on reasonable request.

\section{Consent for publication}

Not applicable.

\section{Disclaimer}

The findings and conclusions presented in this report are those of the authors and do not necessarily reflect the official position of the US Centers for Disease Control and Prevention.

\section{Ethics approval and consent to participate}

Ethical approval from both the Centers for Disease Control Institutional Review Board and the University of Malawi College of Medicine Research and Ethics Committee was granted prior to study implementation. Written informed consent was obtained from patients 18 years and older, or caregivers for incapacitated patients or patients less than 18 years before data collection. If the patient was age 7-18 years and not incapacitated they were asked to provide written assent as well.

\section{Funding}

This work was supported by the US President's Malaria Initiative, US Agency for International Development, under the terms of an Interagency Agreement with the Centers for Disease Control and Prevention (CDC) and through a Cooperative Agreement (Number 5 U01 Cl000189) between the CDC and the Malaria Alert Centre, College of Medicine. The sponsor of the study had no role in study design, data collection, data analysis, data interpretation, or writing of the report. The corresponding author had full access to all of the data from the study and had final responsibility for the decision to submit for publication.

\section{Publisher's Note}

Springer Nature remains neutral with regard to jurisdictional claims in published maps and institutional affiliations.

Received: 20 February 2017 Accepted: 21 September 2017

Published online: 02 October 2017

\section{References}

1. WHO. World Malaria Report 2016. Geneva: World Health Organization; 2016.
2. Steinhardt LC, Chinkhumba J, Wolkon A, Luka M, Luhanga M, Sande J, et al. Quality of malaria case management in Malawi: results from a nationally representative health facility survey. PLoS ONE. 2014;9:e89050.

3. Thwing J, Eisele TP, Steketee RW. Protective efficacy of malaria case management and intermittent preventive treatment for preventing malaria mortality in children: a systematic review for the lives saved tool. BMC Public Health. 2011;11:S14.

4. Barber BE, William T, Grigg MJ, Menon J, Auburn S, Marfurt J, et al. A prospective comparative study of knowlesi, falciparum, and vivax malaria in Sabah, Malaysia: high proportion with severe disease from Plasmodium knowlesi and Plasmodium vivax but no mortality with early referral and artesunate therapy. Clin Infect Dis. 2013:56:383-97.

5. National Malaria Control Programme (NMCP) [Malawi] and ICF International: Malawi Malaria Indicator Survey (MIS). Lilongwe, Malawi and Rockville, Maryland. USA: NMCP and ICF International; 2014. p. 2014.

6. Rutebemberwa E, Kallander K, Tomson G, Peterson S, Pariyo G. Determinants of delay in care-seeking for febrile children in eastern Uganda. Trop Med Int Health. 2009;14:472-9.

7. Tinuade O, lyabo RA, Durotoye O. Health-care-seeking behaviour for childhood illnesses in a resource-poor setting. J Paediatr Child Health. 2010:46:238-42.

8. Njau JD, Goodman C, Kachur SP, Palmer N, Khatib RA, Abdulla S, et al. Fever treatment and household wealth: the challenge posed for rolling out combination therapy for malaria. Trop Med Int Health. 2006;11:299-313.

9. Castillo-Riquelme M, McIntyre D, Barnes K. Household burden of malaria in South Africa and Mozambique: is there a catastrophic impact? Trop Med Int Health. 2008;13:108-22.

10. Asenso-Okyere WK, Dzator JA. Household cost of seeking malaria care. A retrospective study of two districts in Ghana. Soc Sci Med. 1997:45:659-67.

11. Abdel-Hameed AA, Abdalla HM, Alnaury AH. Household expenditure on malaria case management in Wad-Medani, Sudan. Afr J Med Med Sci. 2001;30(Suppl):35-8.

12. The World Bank. Malawi world development indicators; 2016. http://data. worldbank.org/country/malawi. Accessed 17 Feb 2016.

13. Institute of Medicine (US). Committee on the economics of antimalarial drugs. In: Arrow KJ, Panosian C, Gelband H, editors. Saving lives, buying time: economics of malaria drugs in an age of resistance. Washington D.C.: National Academies Press (US); 2004.

14. Chanda P, Masiye F, Chitah BM, Sipilanyambe N, Hawela M, Banda P, Okorosobo T. A cost-effectiveness analysis of artemether lumefantrine for treatment of uncomplicated malaria in Zambia. Malar J. 2007;6:21.

15. Ansah EK, Narh-Bana S, Asiamah S, Dzordzordzi V, Biantey K, Dickson K, et al. Effect of removing direct payment for health care on utilisation and health outcomes in Ghanaian children: a randomised controlled trial. PLoS Med. 2009;6:e1000007.

16. Mota RE, Lara AM, Kunkwenzu ED, Lalloo DG. Health seeking behavior after fever onset in a malaria-endemic area of Malawi. Am J Trop Med Hyg. 2009;81:935-43.

17. Ettling M, McFarland DA, Schultz LJ, Chitsulo L. Economic impact of malaria in Malawian households. Trop Med Parasitol. 1994;45:74-9.

18. Lindblade KA, Mwandama D, Mzilahowa T, Steinhardt L, Gimnig J, Shah M, et al. A cohort study of the effectiveness of insecticide-treated bed nets to prevent malaria in an area of moderate pyrethroid resistance, Malawi. Malar J. 2015;14:31

19. Ewing VL, Lalloo DG, Phiri KS, Roca-Feltrer A, Mangham LJ, SanJoaquin MA. Seasonal and geographic differences in treatment-seeking and household cost of febrile illness among children in Malawi. Malar J. 2011:10:32

20. Shah MP, Briggs-Hagen M, Chinkhumba J, Bauleni A, Chalira A, Moyo D, et al. Adherence to national guidelines for the diagnosis and management of severe malaria: a nationwide, cross-sectional survey in Malawi, 2012. Malar J. 2016;15:369

21. Mathanga DP, Walker ED, Wilson ML, Ali D, Taylor TE, Laufer MK. Malaria control in Malawi: current status and directions for the future. Acta Trop. 2012;121:212-7.

22. Ministry of Health. Malawi health sector strategic plan 2011-2016. Malawi: Lilongwe; 2011. 
23. Meheus F, Boelaert M, Baltussen R, Sundar S. Costs of patient management of visceral leishmaniasis in Muzaffarpur, Bihar, India. Trop Med Int Health. 2006;11:1715-24.

24. Ilunga-Ilunga F, Leveque A, Okenge Ngongo L, Tshimungu Kandolo F, Dramaix M. Costs of treatment of children affected by severe malaria in reference hospitals of Kinshasa, Democratic Republic of Congo. J Infect Dev Ctries. 2014:8:1574-83.

25. Liljas B. How to calculate indirect costs in economic evaluations. Pharmacoeconomics. 1998:13:1-7.

26. Morel CM, Thang ND, Xa NX, le Hung X, le Thuan K, Van Ky P, et al. The economic burden of malaria on the household in south-central Vietnam. Malar J. 2008;7:166

27. Ulandssekretariatet. Malawi: labour market profile. Denmark: Danish Trade Union Council for International Development Cooperation; 2014.

28. Government of Malawi: Employment Act No. 6. 2000. http://www.ilo.org/ dyn/natlex/docs/WEBTEXT/58791/65218/E00MWlo1.htm. Accessed 24 Sept 2015.

29. Demographic and Health Survey: Wealth index. 2016. http://dhsprogram. com/topics/wealth-index/. Accessed 3 Mar 2016.

30. Barber J, Thompson S. Multiple regression of cost data: use of generalised linear models. J Health Serv Res Policy. 2004;9:197-204.

31. Blough D, Ramsey S. Using generalized linear models to assess medical care costs. Health Serv Outcomes Res Method. 2000;1:185-202.
32. Deb P, Manning W, Norton E. Modeling health care costs and counts. iHEA World Congress Sydney, Australia. 2013. http://harris.uchicago.edu/ sites/default/files/iHEA_Sydney_minicourse.pdf (2013). Accessed 1 Sept 2016.

33. Menon MP, Njau JD, McFarland DA. Cost and predictors of care-seeking behaviors among caregivers of febrile children-Uganda, 2009. Am J Trop Med Hyg. 2016;94:932-7.

34. Levey IR, Gitonga N, Smith M, Crosby D, Baleva J, Sanders E, Wakefield A. Malawi private health sector assessment. Bethesda, MD: SHOPS Project, Abt Associates; 2011.

35. Worrall E, Basu S, Hanson K. Is malaria a disease of poverty? A review of the literature. Trop Med Int Health. 2005;10:1047-59.

36. Holtz TH, Kachur SP, Marum LH, Mkandala C, Chizani N, Roberts JM, et al. Care seeking behaviour and treatment of febrile illness in children aged less than five years: a household survey in Blantyre District, Malawi. Trans R Soc Trop Med Hyg. 2003;97:491-7.

37. World Health Organization. Guidelines for the treatment of malaria. 3rd ed. Geneva: World Health Organization; 2015.

38. White MT, Conteh L, Cibulskis R, Ghani AC. Costs and cost-effectiveness of malaria control interventions_a systematic review. Malar J. 2011:10:337.

\section{Submit your next manuscript to BioMed Central and we will help you at every step:}

- We accept pre-submission inquiries

- Our selector tool helps you to find the most relevant journal

- We provide round the clock customer support

- Convenient online submission

- Thorough peer review

- Inclusion in PubMed and all major indexing services

- Maximum visibility for your research

Submit your manuscript at www.biomedcentral.com/submit 